\title{
Developing Learning Analytics for TUT Circle
}

\author{
Anne-Maritta Tervakari, Jarno Marttila, Meri Kailanto, Jukka Huhtamäki, \\ Juho Koro, and Kirsi Silius \\ Hypermedia Laboratory, Department of Mathematics, \\ Tampere University of Technology Tampere, Finland \\ \{anne.tervakari, jarno.marttila,meri.kailanto, \\ jukka.huhtamaki, juho.koro,kirsi.silius\}@tut.fi
}

\begin{abstract}
In this article, we introduce the concept of learning analytics in the context of TUT Circle, a social media enhanced web service for learning in use at Tampere University of Technology. Through three case studies, we apply the methods of learning analytics for insight into the bursty nature of learning activities, procrastination, peer learning, and co-operation between two academic tribes. We found learning analytics useful in providing information to improve the pedagogical practices of online courses, as well as the quality of web-based learning in general.
\end{abstract}

Keywords: Learning Analytics, SNA, Social Media in Learning.

\section{Introduction}

In recent years, social media enhanced learning environments have been a topic of increasing interest, most importantly because they have been seen to promote peer learning by enhancing communication and collaboration within the student community. [1-5] Peer learning includes a selection of learning activities that are mutually beneficial and involve the sharing of knowledge, ideas, and experiences among participants. [6] The use of social media enhanced learning environments can facilitate peer learning by providing collaborative learning tools, and supporting information sharing and distribution of materials. [1-4] However, the effectiveness of the instructions and the learning interventions designed for peer learning is challenging to evaluate. [4],[5],[7] The question is, how do we determine whether, for example, the use of discussion activities has enhanced student participation in the course, or whether the use of group work truly promotes interaction and collaboration between students? [4-5]

A traditional approach for collecting information to evaluate student activity and interaction is to use evaluation surveys at the end of the course. However, these surveys only usually provide limited information for improving teaching or enhancing peer learning. Problems with the traditional approach include: the limited quantity of information collected, and the potentially large delay between the moment of answering the evaluation survey and the actualisation of the interventions, which may debase the quality of self-reported information. [7] 
The use of web-based learning environments provides an opportunity to collect rich data on students' communicative, collaborative, and participative actions throughout courses. However, simple participation statistics may be a poor indicator of student interaction and collaboration if considered alone. [4] The collected data analysed using sophisticated methods can provide useful information on the process of carrying out assignments, communication with other students using forums and private messages, favoured learning materials, and the evolution of the students' online community. [7]

Hypermedia Laboratory at Tampere University of Technology has conducted development projects over several years in order to design and implement a social media enhanced web service TUT Circle for supporting studying and teaching. The development and research of methods of visualisation and analysis of log data for pedagogical purposes has been a significant part of development projects of TUT Circle. The aim of this article is to describe our recent development work related to learning analytics by presenting three teaching experiments. The objectives of these experiments were to: 1 ) find out if the analysis and visualisations of log data provide useful information for improving pedagogical practices of online courses, and 2) collect valuable information for developing tools of learning analytics.

This study is part of a Finnish national project called Campus Conexus, which is being carried out from 2009 to 2013, and is financed by the European Social Fund. Five Finnish universities are participating in the project with an aim to study how students engage in university studies, for example by enriching learning experiences and enhancing students' personal, intellectual, collegial, and professional development. [8]

\section{$2 \quad$ Learning Analytics}

Learning analytics is a relatively new field of science with many definitions [9]. Buckingham Shum and Ferguson [10] state that the background of learning analytics is in web analytics and business intelligence, and that learning analytics may be understood as the use of tools to measure and advance learning and teaching. Siemens [11] defines learning analytics as "use of intelligent data, learner produced data, and analysis model to discover information and social connections and to predict and advice on learning". We see learning analytics more as a process than a set of tools, and approach the definition from the business intelligence viewpoint.

Business and Competitive Intelligence (BCI) is the process in which organisations gather systematically actionable information about competitors and the competitive environment, and ideally apply it to their planning processes and decision making, in order to improve their enterprise's performance and gain insight into externally motivated change, future developments, and their implications to the organisation [12-13]. Following the BCI definition, we define learning analytics as a process or activity in which data on teaching and learning environments is systematically gathered, processed, analysed, and evaluated to support decision making, and to gain insights on teaching and learning.

In this article, we approach the learning analytics process from the data-driven information visualisation point of view, in which data is collected and visualised to amplify users' cognition through expressive, often interactive views (cf. [14]). 
Visualisation has been a key element of social network analysis and its precursor, sociometry, as a tool for exploring the structural configuration of communities, and in sharing the exploration findings to others [15]. While we do realise network visualisations are not enough for learning analytics per se, we see that they do provide a valuable viewpoint in terms of student activity.

TUT Circle, the learning platform utilised during teaching experiments, provides a good environment for applying and further developing methods of: 1) applying social media in learning, and 2) learning analytics. TUT Circle is built on Drupal ${ }^{1}$, a content management framework. TUT Circle contains all the basic functionalities of a modern social media web service, including the possibility to publish several different types of content, e.g. wiki pages, blog posts, news items, and events. TUT Circle also promotes the networking, collaboration, and communications of small groups by allowing users to form friendships with each other, send private messages, chat, create, contribute, and comment on content, exchange opinions, and share resources within and between the groups. When compared to third-party social media platforms, a platform that is maintained by its developers enables collection of rich data as well as the development of new features on the basis of the findings. Many of the features in TUT Circle are developed by integrating and tailoring existing Drupal modules. However, development related to learning analytics has, for now, been done by implementing tailored scripts and batch processes for exporting data directly from TUT Circle database for further analysis. In addition, Google Analytics is used for support in basic Web analytics and benchmark data on TUT Circle usage.

\subsection{Case 1. Interaction between Academic Tribes}

In spring 2011, a cross-university course for students of two different disciplines was organised. During the course, 11 journalism and 5 hypermedia students worked together to design and implement a modern, journalistic online publication. The students were given the opportunity to experience a real-life development project, to learn how to create ideas and communicate to identify user needs, and establish requirements in a multidisciplinary environment similar to real-world design situations. The course met weekly and TUT Circle was used to support communication, collaboration, and information sharing. For example, the students reported their findings and solutions by writing blog messages or wiki pages that all students were able to edit.

Students from different disciplines learn to do things in a way that is typical to their discipline, and use language and concepts they have learned through their study path, which may cause challenges in interaction between students from different disciplines. [16] [17] The objective of this study was to uncover if students used TUT Circle for collaboration. Do students from different disciplines collaborate, or do they work entirely within their own discipline? Log data of students' reading and writing activity collected from TUT Circle was analysed and visualised to show interaction among students and content. [2].

${ }^{1}$ http: / / drupal .org 


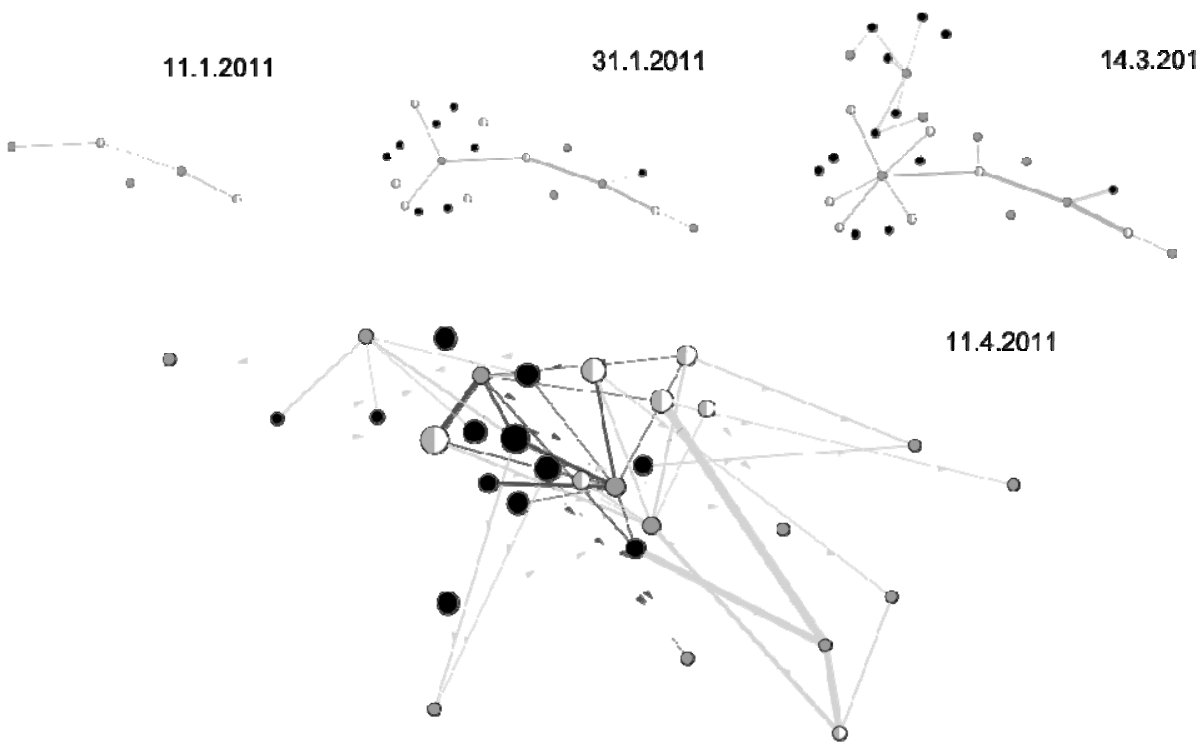

$\circ$

Fig. 1. Two-mode user-to-content network

The data collected from TUT Circle was visualised as a two-mode user-to-content network (See Fig. 1). The figure presents four different phases of the network evolution. The cross-discipline collaboration online started slowly, mainly only when students were asked to contribute to specific documents. Towards the end of the course, however, the cross-discipline collaboration got more intense. In the largest figure, contributions to content (light gray edges), and reading the content (dark gray edges) is visualised. Width of the edge is proportional to the amount of contributions or readings. The visualisation shows students read content produced by other students, especially from other disciplines. However, they seemed to divide into their own groups. For example, hypermedia students in particular read more content produced by journalists. This is reasonable because they need the definitions for implementation of the web-based service according to customer needs. [2]

\subsection{Case 2. Peer Learning}

Programming of Hypermedia is a course that aims to provide students information on different features of hypermedia and web-based services as well as their implementation. Students participating in the course had varying technical skills. It was important to offer them an opportunity to challenge their skills by allowing them 
to freely choose the subject and the techniques for their personal development projects. PHP and CodeIgniter were the only technologies taught during the course in spring 2011. Students were encouraged to report on their projects in TUT Circle so other students could read the reports and learn from them. Students also had opportunities to learn through passive participation, i.e through observation by reading other students' reports. [18] Thirty students reported a total of 137 feature implementations in TUT Circle. The reports were read 1189 times, excluding students reading their own reports. [1]

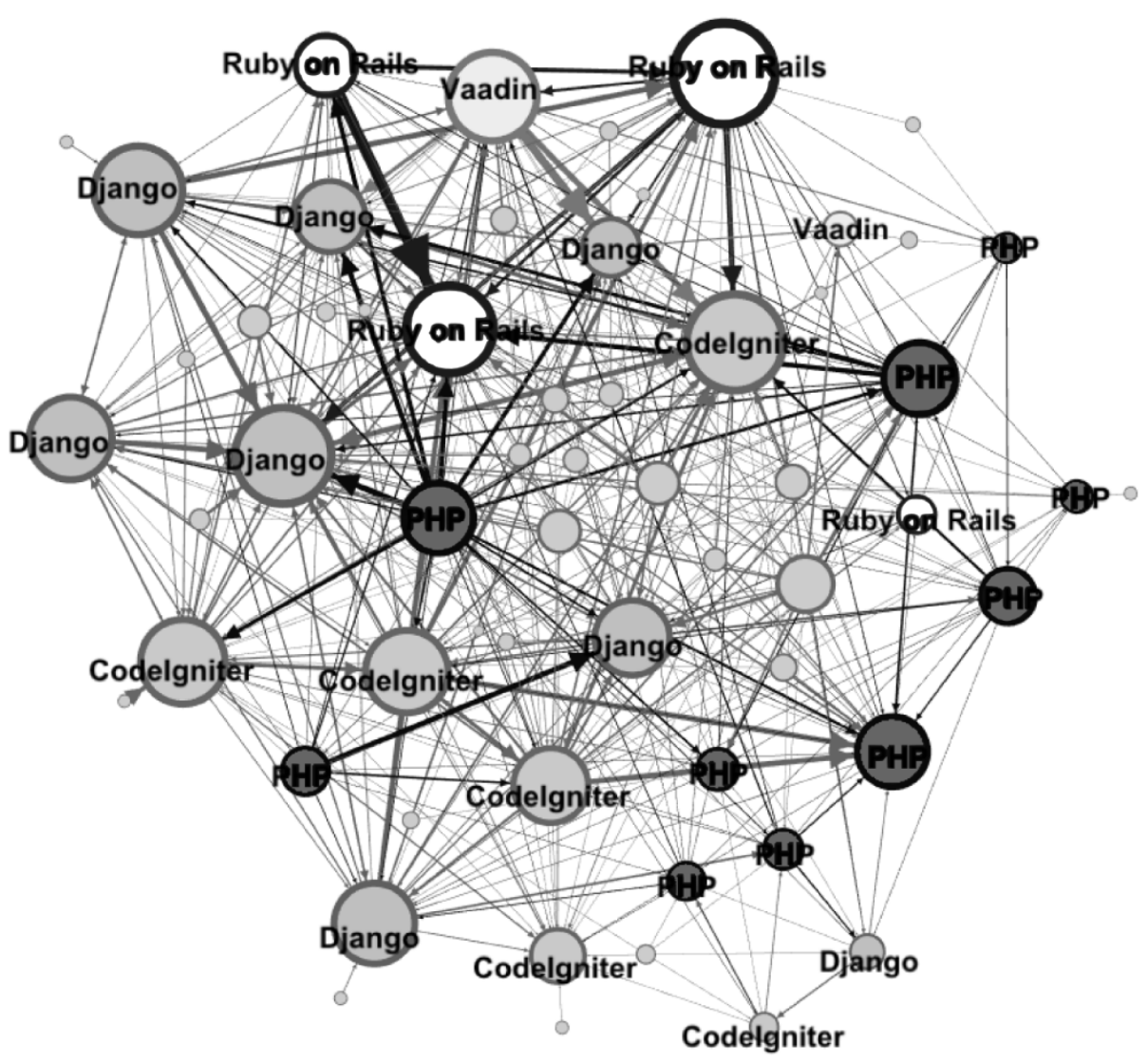

Fig. 2. Network of students in Programming of Hypermedia in spring 2011

We applied network analytics to reveal the peer learning patterns. The network in Figure 2 represents the 1-mode student-student network of students who read each others' contents on different web-programming techniques. Connections between the students are created on the basis of report reading. In the network, the weight of the connection, visualised as edge width, is equal to the number of times a student had read a report by another student. The colour corresponds to the technique the student used in his/her exercises. The network is relatively dense (0.140). Top indegree 
values, i.e. the number of connections pointing to a node [22], are between those using the same technologies; both PHP and alternative technologies are present. The connections between users applying different technologies also exist, but on a smaller scale. The visualisation shows that peer learning has occurred, and students have taken advantage of the opportunity to learn from other students using the same technology. With Gephi ${ }^{2}$, a visual analytical tool for network data, the analyst is also able to explore the peer learner network in detail, including particular analysis of the evolution of peer learner network.

\subsection{Case 3. Procrastination and Other Dynamics of Learning}

Success in online learning requires a high level of participation and good time management skills. Particularly in university students, the main reasons for failing or dropping out from an online course are lack of time coupled with procrastination, the tendency to postpone important tasks. High procrastinators communicate less with their peers because they participate less and later than other students. A high level of procrastination has a negative impact on learning and may lead to poor academic performance. [18], [19]

In autumn 2011, Hypermedia Laboratory organised an online course for 35 students. In order to pass the course, students were required to carry out a group project with an aim to evaluate the quality of web-based service, and to contribute weekly assignments by writing messages in a discussion forum. One of the aims of the study was to monitor and describe the activities of the students in order to examine the phenomenon of participation. [3]

To reveal participation dynamics in a way that supports visual storytelling, a movie-like visualisation of user activities was created using Gource ${ }^{3}$, a software version control visualisation tool which creates animations on the evolution of collaboratively created artefacts. With Gource, a network (or more precisely a tree) of contribution outputs, not contributors, was visualised. The contributors appear in the visualisation as they act.

Figure 3 presents two snapshots of the animation on student participation in their second weekly assignment that required them to write messages in the discussion forum (represented by dark gray). The other content shown in snapshots includes various course information and presentations of study groups. Comments written in TUT Circle discussions are represented as a tree structure under the related node. On the left side, a snapshot from Friday September 15th shows that some students had already submitted their assignments (See snapshot on the up). Most, however, submitted the exercise just before the deadline on Monday September 18th (See snapshot on the bottom). The visualisations show student participation occurred in bursts, and most of the activities took place around assignment deadlines throughout the entire course. [3]

\footnotetext{
2 https: / / gephi.org

3 http://code.google.com/p/gource/
} 


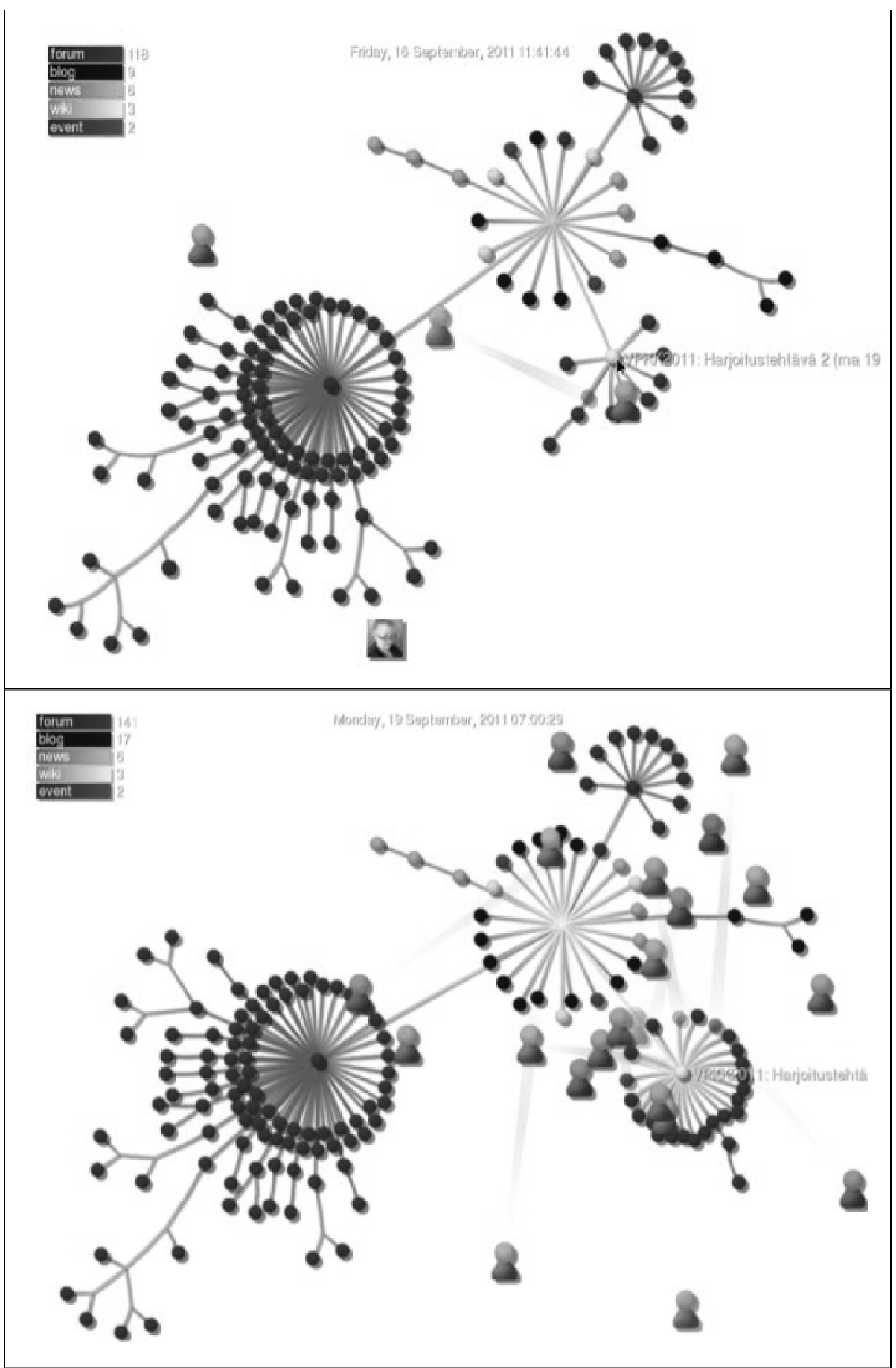

Fig. 3. Two snapshots from an animation visualising the course dynamics 


\section{Discussion and Conclusions}

Learning analytics can be understood as a process of gathering, processing, analysing, and evaluating systematic information about teaching, learning, and learning environments. [9-11] In 2011, Hypermedia Laboratory organised three teaching experiment with an aim to: 1) find out if the analysis and visualisations of log data provided useful information for improving pedagogical practices of online courses, and 2) collect valuable information for developing tools of learning analytics.

In case 1 , the analysis and visualisations of log data made the latent ties among students and contents visible, and offered the teacher possibilities to monitor the evolution of the interaction and collaboration among the students. If, for example, the students' collaboration seems to develop slowly, strategic interventions may be needed to motivate and activate the students. The static representation of the network, like in case 2, provides information about students' active and passive participation. The information may help the teacher identify active students whose reports are most read, or passive students who might have learning problems. In case 3 , the animated visualisation created with Gource demonstrates the phenomenon of procrastination very clearly. Visualisations of the evolution of student participation can help teachers identify students' undesirable behaviour, and provide immediate guidance.

As the results show, learning analytics provides possibilities to verify student interaction and collaboration activities, show latent ties among students and contents, and observe the evolution of student participation. While animated visualisations of the dynamics provides insight into social configurations and the means to share the findings with others, we propose using a more traditional timeline for visualising activity over time for insight into the evolution of participation. [21]

For now, learning analytics have been applied in TUT Circle mainly to support research and the development of the platform. In the near future, we plan to take steps to fully cover the process of learning analytics by developing metrics and visual tools for students and teachers to use in TUT Circle. It's important to understand that human analysis is an essential part of learning analytics, and the tools discussed in this paper are only one part of the entire learning analytics process. For teachers, these kinds of tools can provide valuable insight into student activity and participation, and thus help evaluate the quality of a course's instructional design. The tools may also help students monitor and evaluate their performance processes and learning outcomes, and make strategic adjustments to improve their performance.

While analysis and visualisations of log data can make the actions of students more identifiable, and provide valuable information and insight, human analysis is needed to attach the results to the specific context. For example, the insight of the teacher is needed to understand connections between students' actions, and to plan the pedagogical interventions within the context of the course. Moreover, additional means are still needed to fully understand student behaviour. It is also important to realise that one crucial issue related to learning analytics is the privacy of personal information and the protection of students' identities. It is important to control access to the data collected and analysis results. There is also a need to raise important ethical questions concerning what students need to know about the data collected and analysed, and how students really benefit from being hypermonitored. 


\section{References}

1. Silius, K., Tervakari, A.-M., Huhtamäki, J., Tebest, T., Marttila, J., Kailanto, M., Miilumäki, T.: Programming of Hypermedia: Course Implementation in Social Media. In: Gaol, F.L., Nguyen, Q.V. (eds.) Proc. of the 2011 2nd International Congress on CACS. AISC, vol. 144, pp. 369-376. Springer, Heidelberg (2012)

2. Silius, K., Tervakari, A.-M., Kailanto, M., Huhtamäki, J., Marttila, J., Tebest, T., Miilumäki, T.: Developing an Online Publication Collaborating among Students in Different Disciplines. In: Gaol, F.L., Nguyen, Q.V. (eds.) Proc. of the 2011 2nd International Congress on CACS. AISC, vol. 144, pp. 361-367. Springer, Heidelberg (2012)

3. Tervakari, A.-M., Silius, K., Tebest, T., Marttila, J., Kailanto, M., Huhtamäki, J.: Peer Learning in Social Media Enhanced Learning. In: 2012 IEEE Global Engineering Education Conference (EDUCON), Marrakesh, Morocco, April 17-20 (2012) (in press )

4. Soller, A.L.: Supporting Social Interaction in an Intelligent Collaborative Learning System. International J. of Artificial Intelligence in Education 12, 40-62 (2001)

5. Dawson, S.: 'Seeing' the learning community: An exploration of the development of a resource for monitoring online student networking. British J. of Educational Technology 41(5), 736-752 (2010)

6. Boud, D., Cohen, R., Sampson, J.: Peer learning and assessment. Assessment and Evaluation in Higher Education 24(4), 413-426 (1999)

7. Elias, T.: Learning Analytics: Definitions, Processes, and Potential. Creative Commons, http: / / learninganalytics . net/LearningAnalyticsDefinitionsPro cessespotential.paf

8. Annala, J., Mäkinen, M., Svärd, M., Silius, P., Miilumäki, K.: Online community environment promoting engagement in higher education. SLS Journal - Studies for the Learning Society 2, 75-86 (2012)

9. Long, P., Siemens, S.: Penetrating the Fog: Analytics in Learning and Education. EDUCAUSE Review 46(5), 30-32 (2011)

10. Buckingham Shum, S., Ferguson, R.: Social Learning Analytics. Technical Report KMI11-01, Knowledge Media Institute. The Open University, UK.,

http: / / kmi .open.ac.uk/publications/pdf/kmi-11-01.pdf

11. Siemens, G.: What are Learning Analytics? http://www.elearnspace.org/ blog/2010/08/25/what-are-learning-analytics/

12. Fleisher, C.S., Bensoussan, B.E.: Business and Competitive Analysis: Effective Application of New and Classic Methods. FT Press, Upper Saddle River (2007)

13. Fleisher, C.S., Wright, S.: Competitive Intelligence Analysis Failure: Diagnosing Individual Level Causes and Implementing Organisational Level Remedies. J. Of Strategic Marketing 18(7), 553-572 (2010)

14. Ware, C.: Information Visualization: Perception for Design. Elsevier, San Francisco (2004)

15. Freeman, L.C.: Methods of Social Network Visualization. In: Meyers, R.A. (ed.) Encyclopedia of Complexity and Systems Science. Springer (2009)

16. Becher, T., Trowler, P.R.: Academic Tribes and Territories: Intellectual enquiry and the culture of disciplines. Open University press, Buckingham (2001)

17. Kolb, D.A.: Learning Styles and Disciplinary Differences. In: Chickering, A. (ed.) The Modern American College, Jossey-Bass Publishers, San Francisco (1981) 
18. Michinov, N., Brunot, S., Le Bohec, O., Juhel, J., Delaval, M.: Procrastination, Participation, and Performance in Online Learning Environments. Computer \& Education 56(1), 243-252 (2011)

19. Steel, P.U.: The Nature of Procrastination: a Meta-analytic and Theoretical Review of Quintessential Self-regulatory Failure. Psychological Bulletin 131(1), 65-94 (2007)

20. Tervakari, A.-M., Silius, K., Tebest, T., Marttila, J., Kailanto, M., Huhtamäki, J.: Peer Learning in Social Media Enhanced Learning. In: 2012 IEEE Global Engineering Education Conference (EDUCON), Marrakesh, Morocco, April 17-20 (2012) (in press)

21. Still, K., Huhtamäki, J., Isomursu, M., Lahti, J., Koskela-Huotari, K.: Analytics of the Impact of User Involvement in the Innovation Process and its Outcomes. Case study: Media-Enhanced Learning (MEL) service. In: Proceedings of the 4th World Conference on Educational Sciences, Barcelona, Spain, February 02-05 (2012)

22. Wasserman, S., Faust, K.: Social Network Analysis Methods and Applications. Cambridge University Press, New York (1994) 